\title{
Utilization Of Special Needs Trusts For Disabled Loved Ones
}

Richard Zook, Coastal Carolina University

Holly Crown, Coastal Carolina University

Meyer Drucker, Coastal Carolina University

\begin{abstract}
This paper examines the advantages and disadvantages of using special needs trusts in order to provide assurance that families' loved ones will be able to maintain a satisfactory standard of living while still remaining qualified for certain "needs based" government assistance programs, such as Supplemental Security Income and Medicaid. Legal and/or accounting professionals should be consulted to insure that appropriate decisions are made. As of September of 2002, the U.S. Census Bureau estimated that 32.5 million Americans, or just over 11.5 percent of the population, live with some form of severe disability. ${ }^{l}$ Understandably, families of these disabled individuals often find themselves searching for a way to ensure that their loved one will be provided for, particularly when they are no longer around to support them. Increasingly, these families are turning to special needs trusts in order to provide assurance that their loved one will be able to maintain a satisfactory standard of living. Many considerations, however, must be made by such families in determining if a special needs trust is suitable for their needs. Extensive laws and regulations applicable to special needs trusts may make them less desirable options or preclude a family from taking advantage of them all together. This paper will examine special needs trusts, the advantages and disadvantages of such trusts, and the alternative approaches that may be taken when a special needs trust is found to be unsuitable.
\end{abstract}

\section{BASIC TRUST TERMINOLOGY}

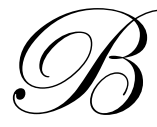

efore a useful analysis of special needs trusts, hereafter referred to as SNTs, can take place, it is necessary to understand a few key terms relevant to all trusts. In general, a trust is a legal agreement between three entities:

- $\quad$ A grantor, who transfers assets to the trust at its inception

- A beneficiary, who receives disbursements from said assets as well as from any income related to them,

- $\quad$ and A trustee, who manages the trust and the disbursements from it.

Often, however, there are not just three parties related to a trust. Multiple grantors, beneficiaries, and trustees can be named to any one trust, and in certain cases, the individuals may actually be the same. Such a case exists in certain "self settled" trusts, in which the grantor also assumes the role of beneficiary. In other cases, the grantor can also be the trustee. In the case of a revocable living trust, the same person can be all three entities.

The assets transferred to the trust are known as the corpus, or principal of the trust. Additionally, income earned by these assets and not subsequently distributed to the beneficiary become part of the corpus. The distribution of the trust's corpus and earnings are established in a written document prepared at the trust's inception known as the Declaration of Trust.

\footnotetext{
${ }^{1}$ U.S. Census Bureau - Americans With Disabilities: 2002, Retrieved Dec. 1, 2007 http://www.census.gov/prod/2006pubs/p70107.pdf
} 
Trusts formed during the lifetime of the grantor are known as inter vivos trusts. In contrast, a trust that is formed upon the death of the grantor is known as a testamentary trust. Further, trusts can be classified as revocable or irrevocable, depending on whether they can be changed or cancelled at any time. Finally, trusts can be established with the assets of the beneficiary, as is the case in self settled trusts, or they can be established using assets from a third party.

\section{WHY CHOOSE A SPECIAL NEEDS TRUST?}

Lawrence A. Friedman, attorney-at-law, wrote that an "SNT is a discretionary trust to provide for a disabled person's needs beyond support." "2 Support, in this case, refers to several governmental benefit programs designed to provide some assistance to disabled citizens. While there are many such programs in existence, the most commonly encountered programs include Supplemental Security Income (SSI), Social Security Disability Income (SSDI), Medicare, and Medicaid.

The preservation of such benefits is generally of paramount importance when considering the formation of a special needs trust. In the case of SSDI and Medicare, no limitations are placed on the amount of assets that the recipient can hold. Anyone can qualify for these programs regardless of their level of income or wealth. As Lawrence A. Friedman points out, "Even Bill Gates could qualify for SSD and Medicare if he should become disabled". ${ }^{3}$ SSI and Medicaid, however, are needs based, and generally require that the recipient possess less than two thousand dollars in assets. Additionally, as SSI is a program designed to provide food and shelter for the recipient, if the individual receives food or shelter from another source, it is deemed as income to the individual which reduces the amount of benefit that can be received from this program. If SSI benefits are reduced to zero by such assistance, Medicaid benefits are generally forgone as well. ${ }^{4}$

It is this limitation that makes the seemingly mundane phrase "beyond support" in Mr. Friedman's quote immensely more pertinent. SNTs seek to bypass these limitations through the phrasing and structure of the trust agreement. The assets in a properly drafted SNT do not count toward the limitation on assets that are held by the beneficiary. Further, in a properly drafted SNT, any payments from the trust made for the beneficiary's expenses will not reduce the amount of Medicaid or SSI benefits that can be received, provided these expenses are not related to food, shelter, or Medicaid covered medical expenses.

Acceptable distributions from SNTs include:

- Recreational or vocational activities;

- $\quad$ Hobbies and vacations (but not lodging since that is shelter);

- $\quad$ Education and training;

- $\quad$ Professional services for the beneficiary;

- $\quad$ Payment for the acquisition and maintenance of a pet or service animal $;^{5}$

- $\quad$ Purchase of a home by the trust with rent payments made by the beneficiary;

- $\quad$ Health and life insurance premiums; and

- $\quad$ Purchase of a car, including maintenance. ${ }^{6}$

\footnotetext{
${ }^{2}$ Lawrence A. Freidman, Special Needs Trusts-- A Comprehensive Overview, Retrieved Dec. 1, 2007, http://www.elderlawanswers.com/resources/article.asp?id=2861\&section=6\&state=

${ }^{3}$ Lawrence A. Freidman, Special Needs Trusts-- A Comprehensive Overview, Retrieved Dec. 1, 2007 http://www.elderlawanswers.com/resources/article.asp?id=2861\&section=6\&state=

${ }^{4}$ DCBA Brief online - March 2006, Retrieved Dec. 1, 2007, http://www.dcba.org/brief/marissue/2006/art40306.htm

${ }^{5}$ American Bar Association, Kristen Lewis Denzinger, Special Needs Trusts, Retrieved Dec. 1, 2007, http://www.abanet.org/rppt/publications/magazine/2003/mj/denzinger.html

${ }^{6}$ Thomas D. Begeley Jr., Third Party Special Needs Trust Section 4.1, Retrieved Dec. 1 , 2007, http://www.njelderlaw.com/elder\%20news/2005/Art-1-5-12-05.PDF
} 
In short, the only limitation placed on the distributions made from SNTs, apart from the fact that they may not be made for expenses covered by the needs based programs whose eligibility they seek to preserve, is the imagination of the drafting agent.

\section{IMPORTANT STATUTORY CONCEPTS RELATED TO SPECIAL NEEDS TRUSTS}

In light of other issues that the Omnibus Budget Reconciliation Act of 1993 (OBRA '93) addressed, many of which were designed to reduce the deficit, those concerning the use of SNTs may seem inconsequential. In an attempt to reduce the deficit, high income families and individuals were subject to higher marginal tax rates of 36 and 39.6 percent, higher AMT tax rates, and limitations on their itemized deductions. ${ }^{7}$ In addition to these provisions OBRA '93 also addressed the treatment of trust amounts in its amendments to 42 U.S.C. 1396p(d), Liens, adjustments and recoveries, and transfers of assets. Paragraphs 4(A) and 4(C) of this section are of particular interest in any discussion concerning SNTs because they set statutory law for the exclusion of the assets held in such trusts in determining an individual's eligibility for medicaid.

Paragraph 4(A) describes how a self settled trust works; it also sets forth the requirements and limitations of such a trust:

(4) This subsection shall not apply to any of the following trusts:

A) A trust containing the assets of an individual under age 65 who is disabled (as defined in section $1382 \mathrm{c}(\mathrm{a})(3)$ of this title) and which is established for the benefit of such individual by a parent, grandparent, legal guardian of the individual, or a court if the State will receive all amounts remaining in the trust upon the death of such individual up to an amount equal to the total medical assistance paid on behalf of the individual under a State plan under this subchapter.

The reader should note that there is an age limit of 65 on the beneficiary of such a trust and that such an individual must also be disabled. Further, while the trust is comprised of the beneficiary's own assets, it must be established by a parent, grandparent, legal guardian, or a court. In addition, there is an obligation on the death of the beneficiary to repay to the state the total amount of medical assistance received by the beneficiary.

Paragraph 4(C) describes those SNTs commonly referred to as pooled or cooperative master trusts. These trusts must meet the following conditions:

C) A trust containing the assets of an individual who is disabled (as defined in section 1382c(a)(3) of this title) that meets the following conditions:

(i) The trust is established and managed by a non-profit association.

(ii) A separate account is maintained for each beneficiary of the trust, but, for purposes of investment and management of funds, the trust pools these accounts.

(iii) Accounts in the trust are established solely for the benefit of individuals who are disabled (as defined in section $1382 \mathrm{c}(\mathrm{a})(3)$ of this title) by the parent, grandparent, or legal guardian of such individuals, by such individuals, or by a court.

(iv) To the extent that amounts remaining in the beneficiary's account upon the death of the beneficiary are not retained by the trust, the trust pays to the State from such remaining amounts in the account an amount equal to the total amount of medical assistance paid on behalf of the beneficiary under the State plan under this subchapter. ${ }^{9}$

\footnotetext{
${ }^{7}$ Congressional Budget Office, $\underline{\text { http://www.cbo.gov/ftpdoc.cfm?index }=4832 \& \text { type }=0}$

${ }^{8}$ U.S. Code, 42 USC 1396p(d)4(A), Retrieved Dec. 1, 2007, http://uscode.house.gov/uscodecgi/fastweb.exe?getdoc+uscview $+\mathrm{t} 41 \mathrm{t} 42+2191+0++\% 28 \% 29 \% 20 \% 20 \mathrm{~A}$

${ }^{9}$ U.S. Code, 42 USC 1396p(d)4(C), Retrieved Dec. 1, 2007, http://uscode.house.gov/uscodecgi/fastweb.exe?getdoc+uscview $+\mathrm{t} 41 \mathrm{t} 42+2191+0++\% 28 \% 29 \% 20 \% 20 \mathrm{~A}$
} 
The beneficiary of such a trust must also be disabled, however there is no age limit set on the individual. Further, the trust must be established by a non-profit association which maintains separate accounts for each beneficiary. Similar to a self settled trust, the account must be established by a parent, grandparent, legal guardian, or a court. In this case, however, the option exists for the beneficiary to establish his or her own account as well. Also similar to a self settled trust, a repayment obligation is placed on the remaining assets in the trust for the medical assistance received by the beneficiary from the state.

As Thomas D. Begley Jr., author of Representing the Elderly Client: Law and Practice points out, there is no federal statutory authority for a third party special needs trust. ${ }^{10}$ However, support for such trusts is set forth in the Social Security Administration's Program Operations Manual System section POMS SI 01120.200. This section describes assets which are not determined to be available to the SSI claimant. SSA Pub. No. 68-0501120 states that "If an individual does not have the legal authority to revoke the trust or direct the use of the trust assets for his/her own support and maintenance, the trust principal is not the individual's resource for SSI purposes." 11 This language provides that a third party SNT must be discretionary and non-revocable in order for the assets contained in them to be considered unavailable to the SSI claimant. Such trusts are not liable to repay the state for Medicaid assistance received and have no imposed age limit on the beneficiary. ${ }^{12}$ Similarly, several states have given third party SNTs statutory authority, as is the case in the state of Illinois' Compiled Statues, section 760 ILCS 5/15.1 which agrees that a third party SNT shall not be liable to repay the state for any Medicaid assistance received. ${ }^{13}$

Figure 1 illustrates the differences between the three types of SNTs.

\begin{tabular}{|l|c|c|c|}
\hline \multicolumn{5}{|c|}{ Special Needs Trusts Comparisons } \\
\hline \multicolumn{1}{|c|}{ Issue } & Third Party SNT & Self Settled SNT & Pooled SNT \\
\hline Who establishes the trust? & $\begin{array}{c}\text { Any third party to the } \\
\text { beneficiary }\end{array}$ & $\begin{array}{c}\text { Parent, grandparent, } \\
\text { guardian, or court }\end{array}$ & $\begin{array}{c}\text { Parent, grandparent, legal } \\
\text { guardian, a court, or the } \\
\text { beneficiary }\end{array}$ \\
\hline Funded by the assets of? & $\begin{array}{c}\text { Any third party to the } \\
\text { beneficiary }\end{array}$ & The beneficiary & $\begin{array}{c}\text { The beneficiary or any third } \\
\text { party }\end{array}$ \\
\hline Who is the beneficiary? & $\begin{array}{c}\text { Disabled person or non- } \\
\text { disabled person }\end{array}$ & Disabled person & Disabled person \\
\hline Must be discretionary? & Yes & Yes & Yes \\
\hline Can the trust be inter vivos? & Can be & Can be & Can be \\
\hline Is the trust testamentary? & Can be & No & No \\
\hline Can the trust be revocable? & No & No & To third parties \\
\hline Distributions made to? & To third parties & To third parties & Yes \\
\hline Is there a payback provision? & No & Yes & Yes \\
\hline Is there an age limit? & No & Yes & \\
\hline
\end{tabular}

The Uniform Trust Code (UTC) was approved by the National Conference of Commissioners on Uniform State Law in 2000, which can have a significant impact on the use of SNTs. Thus far, twenty states have enacted this code into law, though many of them have substantially altered key portions of the text found in it. ${ }^{14}$ It is feared

\footnotetext{
${ }^{10}$ Thomas D. Begley Jr., Third Party Special Needs Trust, Section 2.1.1, Retrieved Dec. 1, 2007, http://www.njelderlaw.com/elder\%20news/2005/Art-1-5-12-05.PDF

${ }^{11}$ Program Operations Manual System, SSA Pub. No. 68-0501120, Retreived Dec. 3, 2007, http://www.achievingindependence.com/Resources\%20for\%20Professionals/SSA/trans35.pdf

${ }_{12}$ American Bar Association, Kristen Lewis Denzinger, Special Needs Trusts, Retrieved Dec. 1, 2007, http://www.abanet.org/rppt/publications/magazine/2003/mj/denzinger.html

${ }^{13}$ Illinois Compiled Statutes, 760 ILCS 5/15.1, Retrieved Dec. 3, 2007,

http://www.ilga.gov/legislation/ilcs/documents/076000050K15.1.htm

${ }^{14}$ CCH-JOURNAL , Journal of Retirement Planning, January-February 2006, M. Merric, The U.T.C.: A Continued Threat to Special Needs Trusts - Part II The Creation of an Enforceable Right in Almost All Discretionary Trusts.
} 
that the UTC may allow the federal government to effectively eliminate third party SNTs by removing the distinction between support and discretionary trusts. ${ }^{15}$ Under the UTC, the asset protection afforded to discretionary third party SNTs is severely crippled because both discretionary trusts and support trusts are treated in the same manner. Under this arrangement, states can rule that the beneficiary of a third party special needs trust has an enforceable right or property interest in the assets contained in the trust regardless of language in the trust contrary to this assumption. This allows creditors to attach a claim on the trust and force payment of such claims. Clearly, the UTC is a threat to third party SNTs which, if adopted by all states, could render the establishment of such trusts impotent.

\section{ADVANTAGES OF SPECIAL NEEDS TRUSTS}

The primary benefit of SNTs is that a claimant of SSI and Medicaid may be the beneficiary of any of the previously mentioned varieties of SNTs and still maintain their eligibility for these programs. This advantage is only gained, however, to the extent that any distributions made from the trust are not in the form of cash or any other benefit covered by such programs. ${ }^{16}$ For this reason, SNTs are commonly referred to as "supplemental needs trusts" because they are designed to supplement, not supplant the benefits received from these needs based programs. ${ }^{17}$

As Jeffrey H. Minde, Esq., the president of the National Special Needs Network points out, another benefit gained through the use of a special needs trust is that any assets held in such a trust are protected from the claims of creditors on the beneficiary. ${ }^{18}$ This applies, however, only to those states which have not enacted the UTC. In such states which have enacted the Uniform Trust Code, any asset protection afforded by the trust is solely the function of a strong spendthrift clause. A spendthrift clause is a provision which states that the trustee of a special needs trust shall not honor any claim made by a third party on the distributions to be made from the trust. ${ }^{19}$

Several tax benefits can be obtained through the use of a special needs trust. For instance, in the case of third party SNTs, as long as the grantor of the trust does not also serve as the trustee as well, any contributions made to the trust in the form of life insurance proceeds or taxable gifts will be considered outside of the grantor's estate at the time of their death. ${ }^{20}$ Additionally, if the grantor wishes to avoid contributions being treated as taxable gifts, they may retain a power of appointment or the right to determine who receives distributions from the trust. Unfortunately, the grantor may choose to avoid the gift tax or the estate tax, but generally, one or the other must be paid.

\section{DISADVANTAGES OF SPECIAL NEEDS TRUSTS}

The restrictions placed on the use of a special needs trust are a major disadvantage of such trusts. The fact that distributions must be designed to supplement needs based governmental aid programs such as SSI or Medicaid rather than supplant them removes much of the freedom of use that would be afforded with other non-revocable trusts. Since distributions of cash directly to the beneficiary will reduce SSI benefits on a dollar for dollar basis, it is generally not desirable to make such distributions to the disabled beneficiary. ${ }^{21}$ Additionally, any distributions made from the trust to the beneficiary in the form of food or shelter (the primary benefits of SSI) will also reduce the

\footnotetext{
${ }^{15}$ CCH-JOURNAL, Journal of Retirement Planning, May-June 2005, M. Merric, The Uniform Trust Code: A Continued Threat to SNTs, Even After Amendment.

${ }^{16}$ Thomas D. Begley Jr., Third Party Special Needs Trust, Section 1.1.2.3.1, Retrieved Dec. 1, 2007, http://www.njelderlaw.com/elder\%20news/2005/Art-1-5-12-05.PDF

${ }^{17}$ Lawrence A. Friedman, Special Needs Trusts - A Comprehensive Overview, http://www.elderlawanswers.com/resources/article.asp?id=2861\&section=6\&state=

${ }_{18}$ Jeffrey H. Minde, Supplemental Needs Trusts: Some Frequently Asked Questions, Retrieved Dec. 3, 2007 , http://www.nsnn.com/Frequently.htm

${ }^{19}$ The Free Dictionary, Retrieved Dec. 3, 2007, http://legal-dictionary.thefreedictionary.com/spendthrift+clause

${ }^{20}$ Thomas D. Begley Jr., Third Party Special Needs Trust, Section 2.4.4, Retrieved Dec. 1, 2007, http://www.njelderlaw.com/elder\%20news/2005/Art-1-5-12-05.PDF.

${ }^{21}$ DCBA.org, DCBA Brief, Retrieved Dec. 3, 2007, http://www.dcba.org/brief/marissue/2006/art40306.htm
} 
benefit received by the beneficiary. Fortunately, this consequence can be avoided by making distributions for food or shelter directly to the third party providing them rather than to the beneficiary themselves. ${ }^{22}$

Another potential disadvantage of the use of an SNT arises out of the designation of the trustee. In general, there are two options available as potential trustees, an unrelated third party such as a financial institution or an attorney, or a related family member or friend. Often times in the case of self settled "type A" trusts, the court will require the appointment of an independent trustee. Whether the grantor decides to establish an independent or related party as the trustee is a critical decision. Related parties may have a better relationship with the beneficiary and thus make better decisions as to their needs and the distributions related to them. Unfortunately, related parties are often ill suited to handle the fiduciary responsibilities of handling such a trust. Additionally, there exists the possibility that the related party trustee is designated as a remaindermen to the trust in which trust assets would be distributed to them in the event of the passing of the beneficiary. In such instances a conflict of interest may occur in which the related party trustee is hesitant to make distributions to the beneficiary in an attempt to maximize their claim on the remaining assets. Independent trustees are generally the favored option because of their knowledge of trust law and their ability to handle the assets in a responsible way. In the case of an attorney with little experience handling such resources, however, the Prudent Investor Act may allow them to appoint a professional money manager. The downfall, of course, is the lack of a close bond between the beneficiary and the trustee. A letter of intent by the grantor will generally reduce this disadvantage by making the acceptable uses of the resources in the trust absolutely clear. ${ }^{23}$ In the case of cooperative master trusts, a nonprofit organization is the trustee. This organization will generally be familiar with trust laws and also sympathetic to disabled individuals. In effect, the best of both worlds is obtained; however, any assets remaining in the trust upon the beneficiary's death revert to the master trust, after repayment is made to the relevant state authorities for benefits received. ${ }^{24}$

\begin{tabular}{|c|c|}
\hline \multicolumn{2}{|c|}{$\begin{array}{r}\text { Figure 2 } \\
\end{array}$} \\
\hline \multicolumn{2}{|c|}{ Comparisons Of The Tax Rates Of Individuals And Trusts } \\
\hline \multicolumn{2}{|c|}{ C } \\
\hline If taxable income is... & The tax is... \\
\hline Not over $\$ 2,150$ & $15 \%$ of the taxable income \\
\hline Over $\$ 2,150$ but not over $\$ 5,000$ & $\$ 322.50$ plus $25 \%$ of the excess over $\$ 2,150$ \\
\hline Over $\$ 5,000$ but not over $\$ 7,650$ & $\$ 1,035.00$ plus $28 \%$ of the excess over $\$ 5,000$ \\
\hline Over $\$ 7,650$ but not over $\$ 10,450$ & $\$ 1,777.00$ plus $33 \%$ of the excess over $\$ 7,650$ \\
\hline Over $\$ 10,450$ & $\$ 2,701.00$ plus $35 \%$ of the excess over $\$ 10,450$ \\
\hline \multicolumn{2}{|l|}{ INDIVIDUALS: } \\
\hline If taxable income is... & The tax is... \\
\hline Not over $\$ 7,825$ & $10 \%$ of the amount over $\$ 0$ \\
\hline Over $\$ 7,825$ but not over $\$ 31,850$ & $\$ 782.50$ plus $15 \%$ of the amount over 7,825 \\
\hline Over $\$ 31,850$ but not over $\$ 77,100$ & $\$ 4,386.25$ plus $25 \%$ of the amount over 31,850 \\
\hline Over $\$ 77,100$, not not over $\$ 160,850$ & $\$ 15,698.75$ plus $28 \%$ of the amount over 77,100 \\
\hline over $\$ 160,850$ but not over $\$ 349,700$ & $\$ 39,148.75$ plus $33 \%$ of the amount over 160,850 \\
\hline Over $\$ 349,700$ & $\$ 101,469.25$ plus $35 \%$ of the amount over 349,700 \\
\hline
\end{tabular}

A major disadvantage of any type of trust is that they have highly condensed tax brackets relative to individuals. For 2007, any income earned by the trust and not subsequently distributed in the excess of $\$ 10,450$ is taxed at 35\%, the highest tax bracket available. In contrast, individual rates do not enter the $35 \%$ marginal tax bracket until they have $\$ 349,700$ in taxable income. ${ }^{25}$ Any income distributed to the beneficiary would be taxed at

\footnotetext{
${ }^{22}$ Thomas D. Begley Jr., Third Party Special Needs Trust, Section 1.1.2.3.1, Retrieved Dec. 1, 2007, http://www.njelderlaw.com/elder\%20news/2005/Art-1-5-12-05.PDF

${ }^{23}$ Thomas D. Begley Jr., Third Party Special Needs Trust, Section 2.6, Retrieved Dec. 1, 2007, http://www.njelderlaw.com/elder\%20news/2005/Art-1-5-12-05.PDF

${ }^{24}$ DCBA.org, DCBA Brief, Retrieved Dec. 3, 2007, http://www.dcba.org/brief/marissue/2006/art40306.htm

${ }^{25}$ West Federal Taxation, 2008 edition, Comprehensive Volume, Chapter 24, Pg. 24-18.
} 
the beneficiary's marginal rate. Figure 2 shows the marginal tax brackets for trusts in 2007 as compared to that of individuals.

\section{ALTERNATIVES TO SPECIAL NEEDS TRUSTS}

There are very few alternatives to SNTs if the family is concerned about their child's SSI or Medicaid eligibility. One alternative is to simply disinherit the child. This is a particularly valid option if the assets of the estate would be modest in comparison to the benefits that would be received from SSI and Medicaid. ${ }^{26}$

If, however, the assets are substantial and the family is concerned with preserving SSI and Medicaid eligibility for the child, the option to transfer assets to a sibling or other related party exists. In this case, the assets would not be in the name of the disabled individual and would not jeopardize their eligibility for such needs based programs. This option, unfortunately, is subject to substantial pitfalls. Many situations could arise in which those assets became subject to the claims of creditors. Further, there is no way to legally force the recipient of the assets to use them for the benefit of the disabled individual. ${ }^{27}$ This situation is generally not advisable, even if the family has absolute trust in the individual they wish to transfer the assets to.

Finally, the family could decide to simply give the child the assets in one way or another. This could be accomplished by simply leaving the assets to the child in a will, by transferring the assets to a trust not designed to preserve SSI or Medicaid eligibility, or by transferring the assets to any number of other financial vehicles. This is a particularly attractive option if the assets the family wishes to transfer to the child substantially outweigh any benefits that may be received by SSI or Medicaid. ${ }^{28}$ Generally, though, given the many acceptable uses of distributions from SNTs, it is not detrimental to the child to set up a special needs trust in order to preserve their eligibility if it can be accomplished.

\section{CONCLUSION}

Planning for your child's future, especially a special needs child, is difficult to accomplish, and for some, it constitutes a great fear. Every parent wants the best for their loved ones, and a special needs trust is an excellent way to allow a disabled child another avenue of income for life's enjoyment that will not jeopardize their eligibility for "needs based" governmental benefits. It is critically important that the family carefully examine who they will name as the trustee of such a trust, the wording that goes in to the establishment of the trust, as well as the tax implications that the formation of such a trust would entail. Choosing the wrong trustee or making one wrong distribution could be detrimental to the child's future benefits, but the advantages of a properly drafted SNT surely outweigh the disadvantages. If the family is unsure of what is best for their situation, consulting a lawyer or CPA proficient in the law surrounding SNTs should provide adequate guidance.

\footnotetext{
${ }^{26}$ See footnote $15-2.4 .1 .1$

${ }^{27}$ Lawyers.com. Special Needs Trusts. http://trusts-estates.lawyers.com/estate-planning/Special-Needs-Trusts.html

${ }^{28}$ See footnote $15-2.4 .1 .2$
} 
NOTES 